\title{
From pink to red. $V$ for Vendetta : trans and queer resistance, straightened out.
}

\author{
Camille Akmut
}

December 9, 2019

\begin{abstract}
A gender-bending, queer, books and roses loving hero restored. The original work is introduced, successive erasures highlighted.
\end{abstract}




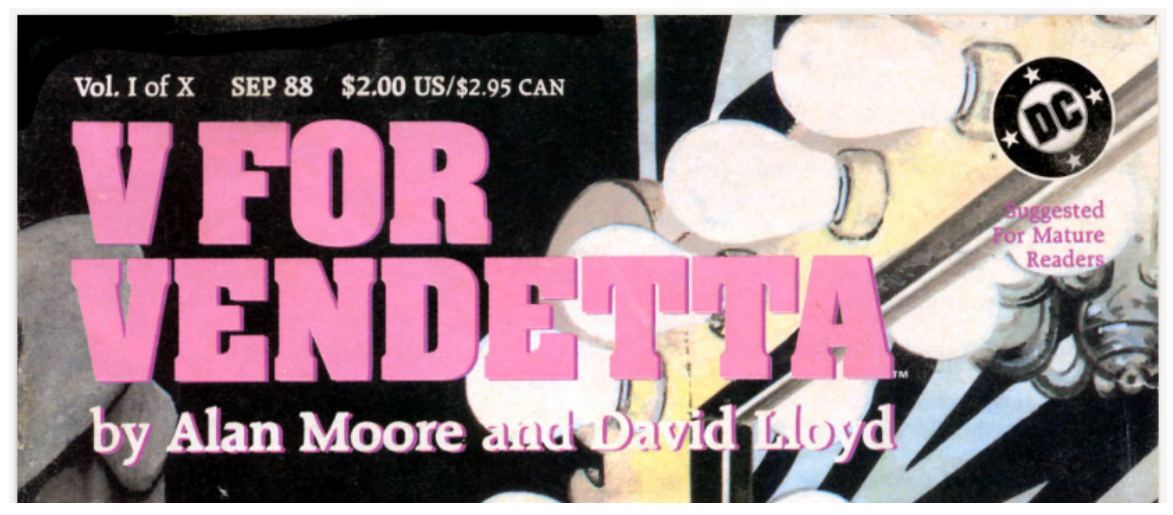

\section{Introduction : queer heroes end up strangled}

Created (over) forty years ago, $V$ for Vendetta has known a strange fate.

Through various new editions, one film adaptation, and following pop culture re-appropriations, gradually most if not all traces of queer and transgender identities have been erased from Alan Moore's first hero.

But, readers of "Vol. 1 of X" of the 1988 color original couldn't have been mistaken : they did not need much sense for imagination to come to other, very different conclusions...

The cover let them know as much : "V FOR VENDETTA" appeared in boldest of pink. Black leather straps, make-up, a woman's wig, an expansive zebra carpet and even a chandelier (!).

(Not even Sebastian's dresser was likely as camp, and a young Boy George's room must have looked not too different - when they had one.)

It warned, in pink too: "for mature readers only".

The introduction from 1988 (1981 reproduction?) came in defense of homosexuals and criticized the stigmatization of AIDS in Thatcher's England.

In the 1990's edition, that introduction was replaced with a more mainstream and acceptable story about an episode of Lloyd at a bar, and references to the barman's wife. The original foreword was pushed back...

The 2005 Hollywood movie starred glamour girl Nathalie Portman and returned 100 million $\$$. Valerie and other homosexual characters were partly preserved, but the more complicated, irrecuperable case of "V" mostly skipped, and silenced.

A superhero with a geographical twist : Superman or Spiderman flying, gliding among London row houses instead of New York skyscrapers...

Let another forty years pass : And, even less will be left from the story written long ago by a brilliant and original British writer of working-class origins...

He himself had no problems admitting to it : he had written The Doll about a "transsexual terrorist", which served as basis, and cited David Bowie as influence. 


\section{How it all started : Vol. 1, November 5th}

A 16 year old girl puts on pink lipstick in preparation for survival sex;

On the radio meanwhile, chauvinist propaganda mixes exhalation of patriotism and dominant discourses of heterosexual masculinity :

"It is the duty of every man ... to ... make [their country] great again." (p. 3)

These oddly foretelling words recall the current U.S. presidency, whose slogan is the same;

Cameras with labels "for your protection" remind of present mass surveillance techniques.

The very first picture of our flawed hero - introduced as "villain" shows them walking towards the beauty dresser, the same as the one shown on the cover. Not shown : them putting on a brunette wig, rouge and powder...

On the upper shelf of the bookcase, from left to right : Mein Kampf, Capital, Uncle Tom's Cabin and (Thomas More's?) Utopia.

The posters on the wall are of 1930's horror films Murders in the Rue Morgue and Son of Frankenstein, and another Karloff poster, the gangster movie White Heat (1949) with James Cagney, and the comedy Road to Morocco (1942) with Bing Crosby.

- Frankenstein : parts that don't fit together.

Religion : the other refuge of the scoundrel after nationalism, patriotism. "Purity through faith" a poster advertizes.

Against the police, $\mathrm{V}$ uses their own weapons : tear gas. All the while reciting lines from Macbeth's first act. "Come we must prepare for the first act", they later say to their new companion.

In addition, a fake hand turns out to be a bomb.

The poor girl saved from an obviously corrupt police, nonetheless not free from the system having created it, exclaims :

"But, that's against the law!" - as V goes from setting a policeman on fire, to bombing an entire government building.

$\mathrm{V}$ liberated her with one act, but thousands of others with that other : "all over London" people marvelled at images of a Parliament in flames.

This ends with a pink-purple and black illustration showing $\mathrm{V}$ helping the for now equally nameless girl reach their level.

The same choices of color are found later, when in chapter $3 \mathrm{~V}$ leaves behind a black graffiti (the anarchist symbol except upside-down) and a pink rose as signature.

Just as more expressions of misogyny are given :

"Myself, I've always been a ladies' man. Tales I could tell you about when (...) Porky (...) and myself met these two native gels..." (p. )

- an overweight and overzealous government lackey tells.

More books on shelves : Hard Times by Dickens, Dante's Divine Comedy, two volumes of Shakespeare, Homer's Iliad and Odyssey, and various historical books ("French Revolution" and "Decline and Fall of [the Roman Empire]")... (Aeneid was not included for good reason, probably.) 


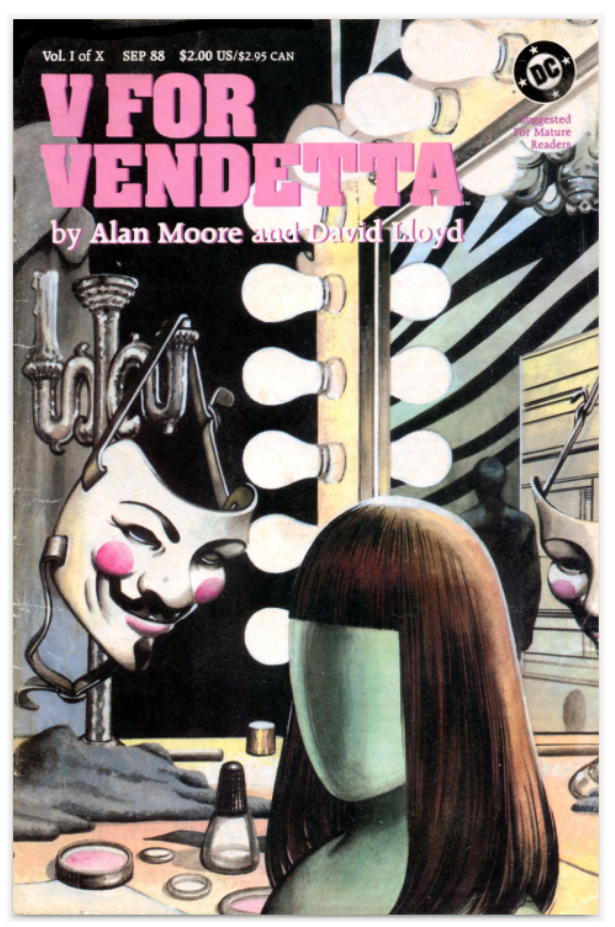

(a) original 1988 colour cover

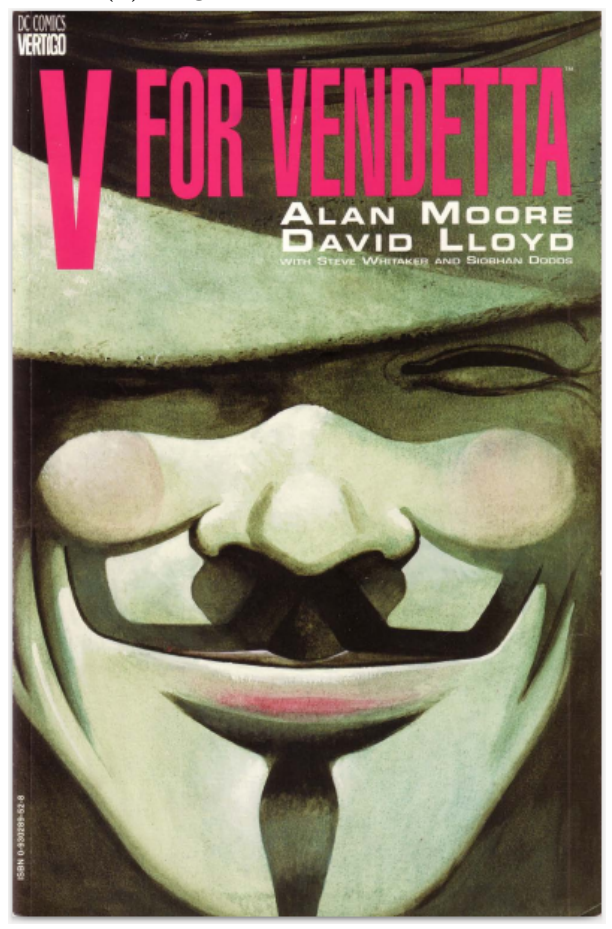

(b) 1990 "collected" edition 
In a society that had eradicated culture, "they eradicated some cultures more thoroughly than others" V notes.

$\mathrm{V}$ had foreseen their own fate in that moment.

And, so, a bold pink was replaced with a pale red... ${ }^{1}$

"The government has expressed a desire to eradicate homosexuality", Moore wrote himself in the original introduction. "(...) and one can only speculate as to which minority will be ... next", he went on.

'Volume 1 of X' of this complicated book - written with interruptions over a period of multiple years (if not decades) - had created an intellectual, flamboyant hero of uncertain, disguised sexuality and gender identity.

Moore must know by now which minorities were next amongst people who do not fit in society's predominant models of proper ways of being and behaving; most obvious those whose gender identity and expressions cannot be hidden under the triumphant right-wing alliance of Trump-Johnson, Bolsonaro and co..

Let this be known : $V$ for Vendetta is a story of queer resistance.

You can interpret that word however you like - as long as not straight.

This transgender hero - both sensitive and sensible - was anything but.

\footnotetext{
${ }^{1} \mathrm{~A}$ decade later, that red became even darker for the film poster.
} 


\section{REFERENCES}

- Moore, Alan with Lloyd, David. $V$ for Vendetta. Two colour editions by DC comics were discussed here : 1988 and 1990 .

- Moore, Alan. 1983. Behind the Painted Smile.

- Moore, Alan. The Doll. (Rejected, and unpublished?)

- Virgil. Aeneid. Trans. R. Fitzgerald. (Celebration of Rome, but Book II remains one of the most harrowing accounts of the horrors of war : "the occupied are carried by one : no hope for everyone.")

— McTeigue, James (dir.), Wachowskis (script). 2005. V for Vendetta.

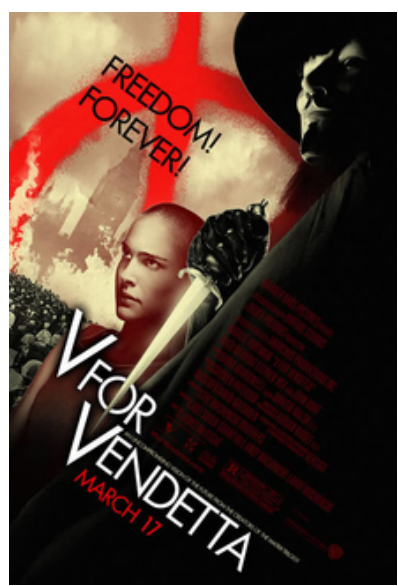

ps. In the original introduction Moore wondered why he was telling stories about his daughter. We can answer that question for him : he, his agents or publishers, had probably feared he would be mistaken for a homosexual himself. That's how queer "V" was... - everyone knew, and there was no mistake about it for anyone, then. 